\title{
Carbon Capture, Utilization and Storage (CCUS) in Power Plants of Bangladesh
}

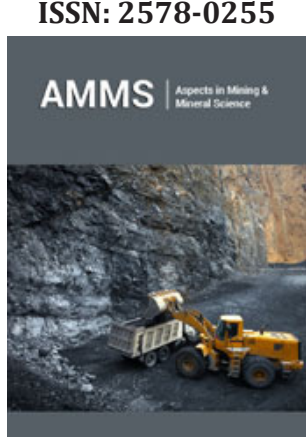

*Corresponding author: Mohammad Ismail, Associate Professor, Dept. of Applied Chemistry \& Chemical Engineering, University of Dhaka, Bangladesh

Submission: 監 July 25, 2019

Published: 侮 August 12, 2019

Volume 3 - Issue 3

How to cite this article: Mohammad I, Carbon Capture, Utilization and Storage (CCUS) in Power Plants of Bangladesh, Aspects Min Miner Sci.3(3) AMMS.000563.2019.

DOI: 10.31031/AMMS.2019.03.000563

Copyright@ Mohammad Ismail PhD, This article is distributed under the terms of the Creative Commons Attribution 4.0 International License, which permits unrestricted use and redistribution provided that the original author and source are credited.

\section{Mohammad Ismail, $\mathrm{PhD}^{*}$}

Associate Professor, Dept. of Applied Chemistry \& Chemical Engineering, University of Dhaka, Bangladesh

\section{Abstract}

The main objective of this paper is to analyze the power and energy sector of Bangladesh, carbon dioxide emission from power sector and future possible clean energy options for Bangladesh. It also explores the challenges in the pathway of carbon capture, utilization and storages (CCUS) and to put forward a set of recommendations on long term sustainability.

Keywords: Carbon Capture; Power plants; Electricity; Utilization

Abbreviations: CCUS: Carbon Capture; Utilization and Storage; GHG: Greenhouse Gas; CLC: Chemical Looping Combustion Technology; CDM: Clean Development Mechanism

\section{Energy Sector of Bangladesh}

The energy sector of Bangladesh has experienced considerable progress in meeting the demand for electricity of the country. The electricity plays a critically important role in the country's development. Bangladesh is now shifting in a status of developing country from the least developed country. In the recent years, massive industrialization is going on and the country's demand for electricity is dramatically increasing. The energy sector of Bangladesh is mostly depending on the fossil fuel especially on natural gas and coal owing to their low cost, availability as well as existing reliable technology for energy production.

\section{Power Plants of Bangladesh}

There are 134 power plants (Source- Power division, 2018) in Bangladesh and among these, 121 are in operation and some are in construction phase. The fuel used for the electricity production can be categorized are as follows: 64 plants are run by natural gas, 40 plants use furnace oil, 13 plants use diesel and 2 plants are using coal as fuel (three more are under construction). There are also one hydro-power plant and some Solar PV power plants over the country. The electricity generation in Bangladesh is predominantly from domestic natural gas (61\% as in 2018). However, since the domestic NG resource is declining and the demand for electricity is increasing, to meet the demand of electricity, GoB is going to set up more Coal fired, and LNG fired Power Plants along with the Nuclear Power Plants. Besides these, as a part of government's Master Plan 2010, a number of private quick rental power plants (from private sectors) are in market that are supplying the electricity to the national grid and supporting to reduce power shortage in the short-run. In the recent years, the country is giving more focus on the coal fired power plants owing to a number of factors including 1) depletion of the natural gas resources, 2) proper utilization of the available coal in the country, 3) Low price of coal in international market etc. The coal available in the country is mostly in the rank of bituminous form. It is notable that the quality of coal is determined by the amount of moisture, fixed carbon, volatile matter, ash and total sulfur present. Currently, the country has one coal fired power plant (Boropukuria Coal fired Power Station) in operation. As per Government plan, by 2025, there will be 8-9 coal fired power plants. Among these, Rampal and Matarbari Phase-1 are in construction Stage. The others are in still planning Phase [1,2].

\section{Carbon Capture, Utilization and Storage (CCUS)}

Global warming is one of the most crucial environmental issues and increase in the greenhouse gas (GHGs) concentrations is causing the global climate change. Among different $\mathrm{GHGs}, \mathrm{CO}_{2}$ is the major source in terms of global warming potential and the concentration in the 
atmosphere. According to the latest scientific evidence on climate change, including last year's IPCC Special Report on Global Warming of $1.5^{\circ} \mathrm{C}$, the level of GHGs in the atmosphere have increased largely due to human activity (anthropogenic) and causing the Earth's temperature to rise. The dependency on fossil fuels for energy production, especially in the electricity and transportation sectors, has resulted in an increase in $\mathrm{CO}_{2}$ concentration in the atmosphere. Globally, $67 \%$ of the electricity are producing from conventional fuels. Carbon Capture and Storage (CCS), more broadly, Carbon Capture, Utilization and Storage (CCUS), is a vital climate mitigation technology for low-carbon energy future. CCS is a proven and highly versatile technological option for clean fuel production. The IEA CCS Roadmap highlighted that CCS will need to play a significant role in achieving an atmospheric $\mathrm{CO}_{2}$ concentration stabilization of 450 ppm by 2050 [3]. In that scenario it is expected that CCS will provide approximately $14 \%$ of the total $\mathrm{CO}_{2}$ emissions reduction out to 2050. Depending on the process involved in power plants, four major strategies exist to capture $\mathrm{CO}_{2}$ : post-combustion, precombustion, oxyfuel combustion and chemical looping combustion technology (CLC) [4]. The choice of technology is determined largely by the process conditions under which it may operate. The recent development in CLC is the simultaneous production of pure hydrogen along with the carbon capture is expected to bring a drastic change in the hydrogen fuel economy and carbon capture in the power plants [5].

The implementation of CCS depends on a number of factors but mostly on price for carbon dioxide in the global market. The carbon price varies from developed country to developing countries. A well cap-and-trade policy implementation and the necessary policy framework for CCS are deployed in the leading developed countries
[6] whilst the developing countries are far away in this regard and merely challenging to implement such policies for developing countries. However, alternative carbon pricing mechanism like CDM (Clean Development Mechanism) can provide a win-win solution for CCUS in the developing countries like Bangladesh.

\section{Is Bangladesh Ready for CCUS?}

The $\mathrm{CO}_{2}$ emission trend of the Bangladesh from 1972 to 2014 are shown in the Figure 1. According to this (Figure 1), the $\mathrm{CO}_{2}$ emission from various industrial sectors especially from power plants and cement factories is increasing drastically. The recent report of Third Nation Communication of Bangladesh shows that, in 2012, the $\mathrm{CO}_{2}$ emission from energy industries was 29,130 Gigagrams (Gg) whilst the emission from manufacturing and construction sector was 20,018Gg and from transport sectors was 8,442Gg [7]. Assuming that Bangladesh's GDP will grow at an average of 7.0 percent per year, the business-as-usual (i.e., assuming that there will be no improvements in Bangladesh's energy efficiency and no change in Bangladesh's carbon intensity) case, the GHGs emission from power sector will be $91.42 \mathrm{MtCO}_{2} \mathrm{e}$ in 2030 . This amount is 336\% increase in comparison to emission in 2011 [7] and it is expected that the $\mathrm{CO}_{2}$ emission will be 32 times higher (Considering benchmark scenario) by 2050 [8]. It is notable that, to date, the Government of Bangladesh has not introduced any policies or legislation dedicated to encouraging the development of CCS (or CCUS) in the power plants or any other sectors. The global community are now focusing on the development that could contribute to lower long-run $\mathrm{CO}_{2}$ emissions. Concerning the effects of GHGs emissions on environment, health, economics and development, it is the best time for Bangladesh to formulate roadmap of CCUS and to ensure a safe and secured future nation.

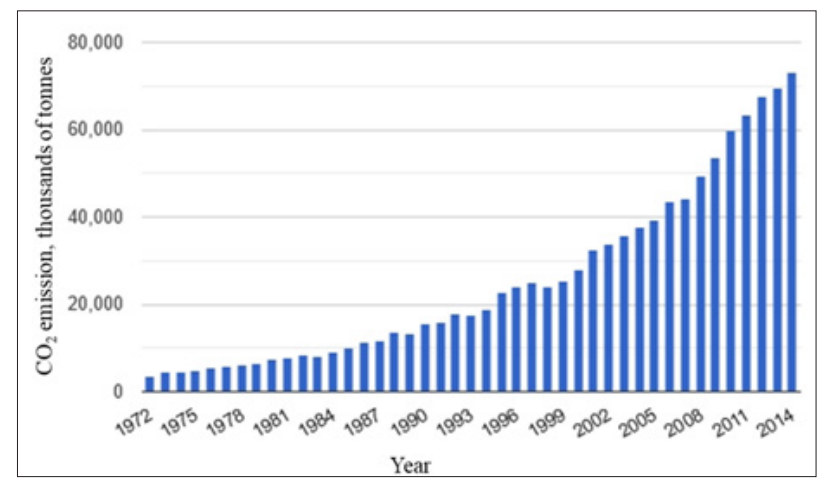

Figure 1: Carbon dioxide emissions history of Bangladesh from 1972 to 2014 [6].

\section{Actions that can be taken by Bangladesh}

Bangladesh clearly needs to deploy the CCUS in the existing and upcoming power plants. Furthermore, it also needs to diversify and expand its power generation system. The country should set up of a new emissions target say a net-zero greenhouse gases by 2050 . This will help to accelerate and explore the clean technologies in the power sector. Globally, to deploy the CCUS technology, availability of proven technology, demand in Market as well as policy regulation and framework are important. Furthermore, investments in clean energy production and technology as well as incentives (from Government and donor agencies) in the form of climate or green fund are essential to promote the CCUS in the developing countries like Bangladesh. Among various policies, the Government should support R\&D for new technology options and for development of pilot scale CCUS facilities. It is notable that new technologies do not jump directly from the lab scale or pilot stage to full-scale operation. Hence set up of demonstration scale both for capture, utilization and storage will help in capacity and expertise development of the country. The identifying promising concepts, taking the prompt 
decision, quantify the technical risk (short, mid-term and long term) and incentive for commercial deployment of the low carbon i.e., clean technologies are essential for ensuring future green environment. Use of captured $\mathrm{CO}_{2}$ for various industrial processes and for the production of green products must be explored [9]. Besides this, there should have dedicated storage system for $\mathrm{CO}_{2}$.

The government of Bangladesh should actively think about the CCS-ready power generation technology in the upcoming power plants especially coal fired power plants and possible retrofitting of the CCS in the existing power plants. Hence, it is necessary to carry out a site-specific techno-economic feasibility study for CCUS in the Bangladesh. The deployment of CCUS in Bangladesh will enrich the country's fame in promoting the green technology like the activities put forward for the phase down the manufacture and use of Hydrofluorocarbons (HFCs) [10]. In this regard, Bangladesh can look for technical and financial support from international agencies e.g., Green Climate Fund (GCF) and Global Environment Facility (GEF).

\section{Conclusion}

There is a considerable opportunity for Bangladesh to boost the economic growth via application of green technology. This development could easily be made sustainable through the deployment of CCUS, at least, in the upcoming power plant. Nevertheless, a more shift in the renewable sources for secured energy will help the country to move forward for green growth.
Improvement in energy efficiency would also help to get a significant response from the international financial system that will allow Bangladesh to be benefited from a diverse, ecofriendly, secure and deflationary energy supply. The sooner the country will realize that CCUS in the power plants and related industrial sectors is appropriate technology, the better future in the green economy will be ensured for the country.

\section{References}

1. Bangladesh Power Development Board.

2. 2016, Bangladesh National Conservation Strategy (Power Part).

3. IEA (2013) Technology roadmap-carbon capture and storage, France.

4. Holloway S (2007) Carbon dioxide capture and geological storage. Phil Trans R Soc A 365(1853): 1095-1107.

5. Ismail M, Liu W, Chan M, Dunstan MT, Grey C, et al. (2016) Synthesis, application, and carbonation behavior of $\mathrm{Ca}_{2} \mathrm{Fe}_{2} \mathrm{O}_{5}$ for chemical looping $\mathrm{H}_{2}$ production. Energy \& Fuels 30(8): 6220-6232.

6. TheGlobalEconomy.com, Bangladesh: Carbon dioxide $\left(\mathrm{CO}_{2}\right)$ emissions.

7. 2018, Third National Communication of Bangladesh to The United Nations Framework Convention on Climate Change, MoEFCC, GoB.

8. Gunter BG (2010) The impact of development on $\mathrm{CO}_{2}$ emissions: A case study for Bangladesh until 2050.

9. Pfennig A (2019) Sustainable Bio-or $\mathrm{CO}_{2}$ economy: Chances, risks, and systems perspective. ChemBioEng Rev 6(3): 90-104.

10. Faisal AM, Ismail M, Purkayastha SK (2018) Promotion of green technology: Bangladesh's achievements. The Independent, Bangladesh. 